\title{
Presentation of Childhood Systemic Lupus Erythematosus in a Tertiary Care Hospital
}

\author{
SHAHANAARAHMAN ${ }^{1}$, MOHAMMAD IMNUL ISLAM ${ }^{2}$, MANIK KUMAR TALUKDER ${ }^{3}$, MOHAMMED \\ MAHBUBUL ISLAM ${ }^{4}$, SYED SAIMUL HUQUE ${ }^{5}$, RANJIT RANJAN ROY ${ }^{6}$
}

\begin{abstract}
:
Background: Systemic lupus erythematosus in children (Paediatric SLE / pSLE) may have a great variability in disease presentation. Any organ system can be involved in pSLE leading to protean clinical manifestations. To evaluate the clinical and serological presentation of pSLE in tertiary renter Bangladesh and to compare it with other populations.

Methodology: It was a retrospective cohort study carried out in the department of Paediatrics, Bangabandhu Sheikh Mujib Medical University, Dhaka during the period of January 2005 to December 2013. A total of 70 patients fulfilling the 1997 revised ACR classification criteria for SLE were enrolled in the study. Data was collected in a pre-designed questionnaire.

Results: Age range was 2.5 years to 16 years, female: male ratio was 7:1. Duration of disease was 1 month to 18 months. Common clinical presentation included general weakness/fatigue (91\%), fever (83\%), arthralgia/arthritis (74\%), oral ulcer (73\%) and skin rash (71\%). All the patients were anemic. ANA was positive in $97 \%$ cases and anti-ds DNA in $91 \%$ cases. More than $65 \%$ cases had evidences of renal involvement at the presentation. Among the patients who underwent kidney biopsy, 40\% had diffuse proliferative lupus nephritis (WHO class IV) followed by class III in $26 \%$ cases.

Conclusion: Pediatric SLE patients in our country, compared to other countries had much higher incidence of fever and non-specific complaints such as, general weakness and malaise as presenting symptoms. Thus, a strong index of suspicion should be maintained for early diagnosis of pSLE especially among adolescent girls.
\end{abstract}

Key Words: pSLE, Clinical presentation, Laboratory findings.

\section{Introduction:}

Systemic lupus erythematosus in children and adolescents (pSLE) may have a great variability in disease presentation and course ${ }^{1,2}$. Any organ system can be involved in SLE, so the potential clinical manifestations are protean ${ }^{1,2,3}$. They frequently

1. Professor, Paediatrics, Bangabandhu Sheikh Mujib Medical University, Dhaka

2. Associate Professor, Paediatrics, Bangabandhu Sheikh Mujib Medical University, Dhaka

3. Assistant Professor, Paediatrics, Bangabandhu Sheikh Mujib Medical University, Dhaka

4. Assistant Professor, Paediatrics, Bangabandhu Sheikh Mujib Medical University, Dhaka

5. Assistant Professor, Paediatric Nephrology, Bangabandhu Sheikh Mujib Medical University, Dhaka

6. Associate Professor, Paediatric Nephrology, Bangabandhu Sheikh Mujib Medical University, Dhaka

Correspondence: Shahana A Rahman, E-mail: shahana2pd @yahoo.com present with systemic, constitutional symptoms such as fever, diffuse hair loss, fatigue, weight loss and diffuse generalized inflammation in addition to specific organ involvement. A thorough literature review finds that the incidence of pediatric SLE ranged from 0.36 to 2.5 per 100,000 per year. The prevalence of pSLE ranged from 1.89 to 25.7 per $100,000^{4}$. Studies found differences in presentation of pSLE among different ethnic groups 5,6 . Reports are available showing paediatric SLE presenting with more acute illness and having more frequent renal, hematological and neurological involvement at the time of diagnosis compared to adult SLE 7 . Non-specific presentations like recurrent infection or fever was found to be the commonest presentation (90\%) in a small series of pediatric SLE patients in Bangladesh reported in $2008^{8}$. Other than that no study had been done 
regarding the presentation of pSLE in the country. The present study is an extension of 2008 case series including cases up to December 2013. Objectives of this study were to evaluate the clinical and serological presentation of pSLE in a tertiary referral hospital of Bangladesh and to compare it with those in other populations.

\section{Methodology:}

It was a retrospective study carried out in the Department of Paediatrics, Bangabandhu Sheikh Mujib Medical University (BSMMU), Dhaka.

All the patients attending the paediatric rheumatology follow up clinic and paediatric ward during the period of January 2005 of December 2013 were included in the study.

The Department of Paediatrics has been running a paediatric rheumatology clinic twice a week since the year 2000 , which is the only paediatric rheumatology clinic in the country. Since 2005 this clinic has been running in a more organized way and all the case records are preserved. Patients attend this clinic from different parts of the country. Before visiting the clinic, most of the patients visited other hospitals or clinicians including GPs, paediatricians and adult physicians.

Patients who fulfilled 4 or more criteria of the 1997 revised American College of Rheumatology (ACR) classification criteria for SLE, either at presentation or sequentially were considered as SLE. ${ }^{1}$ Children below the age of 16 years from both the sexes fulfilling the ACR criteria were included in the study.

All the case records were reviewed by two trained paediatric rheumatologists. Age, gender and clinical features at initial diagnosis were recorded in a data collection from. Laboratory investigations in addition to immunological and pathological findings at diagnosis were also recorded. Laboratory investigations included urinary, haematological and radiological findings. The immunological parameters included antinuclear antibodies (ANA), anti dsDNA, $\mathrm{C}_{3}$ and $\mathrm{C}_{4}$. ANA was determined by immunofluorescence technique using Hep-2 cells as substrate. Anti-double stranded DNA (Anti-ds DNA) was measured by ELISA method. Complements were measured by nephlometry.

Histopathological evaluation of kidney biopsy specimen in patients with lupus nephritis was done. The renal histopathology was classified according to modified World Health Organization (WHO) classification ${ }^{9}$.
The clinical features that were recorded included constitutional symptoms such as fever, general weakness, cutaneous, mucosal, articular, renal, CNS manifestations, generalized lymphadenopathy and hepatosplenomegaly. Urine analysis and urinary total protein (UTP) were also recorded.

Auto-immune hemolytic anemia was diagnosed by positive Coomb's test. Leucocytopaenia was considered when total WBC count was less than 4000/ $\mathrm{cmm}$. Similarly thrombocytopenia $\left(<1000,000 / \mathrm{m}^{3}\right)$ in the absence of any offending drugs, proteinuria (0.5g/24 hrs or more), hematuria (>5 RBC/HPF) were recorded. Pleural effusion and pericardial effusion were documented by positive clinical findings as well as radiological and echo-cardiographic findings.

All the data were tabulated and calculated manually. Results were expressed as mean, standard deviation, range and frequency.

\section{Results:}

A total of 70 patients were enrolled in the study. Age range at diagnosis was 2.5 years to 16 years, mean age being 11.6 years. Female: male ratio was 7:1. Duration of disease at presentation was 1 month to 18 months, mean being 09.5 months.

General weakness or fatigue (91\%), fever (83\%), arthralgia/arthritis (74\%), oral ulcer (73\%) and skin rash $(71 \%)$ were most common clinical features at disease onset (Table-I).

Table-I

Clinical presentation of SLE in children $(n=70)$

\begin{tabular}{lcc}
\hline Symptoms & Number & $(\%)$ \\
\hline Gen. weakness/Fatigue & 58 & 91 \\
Fever & 64 & 83 \\
Arthralgia/Arthritis & 52 & 74 \\
Oral ulcer & 50 & 73 \\
Skin rash & 51 & 71 \\
Photosensitivity & 41 & 59 \\
Alopecia & 36 & 51 \\
Asciter & 11 & 16 \\
Headache & 31 & 44 \\
Convulsion & 18 & 26 \\
Scanty urine & 16 & 23 \\
Oedema & 14 & 20 \\
Hepatomegaly & 32 & 46 \\
Hypertension & 24 & 35 \\
Splenomegaly & 18 & 26 \\
Generalized Lymphadenopathy & 11 & 16 \\
Dyspnea & 09 & 13 \\
Pleural effusion & 07 & 10 \\
Pericardial effusion & 04 & 06 \\
\hline
\end{tabular}


When laboratory findings were analyzed, 100\% patients were found to have anemia (hemoglobin range: $4.4-10.2 \mathrm{mg} / \mathrm{dl}$; mean $8.5 \mathrm{mg} / \mathrm{dl}$ ). Auto immune hemolytic anemia was found in $16 \%$ patients. Thrombocytopenia and leucocytopenia was present in $17 \%$ and $10 \%$ patients respectively. Urinary total protein was high in $59 \%$ cases. ANA was positive in $97 \%$ and Anti ds DNA in 91\% cases. Low C3 and C4 were found in $83 \%$ and $84 \%$ patients respectively (Table-II).

Table-II

Laboratory parameters of pSLE cases ( $n=70)$

\begin{tabular}{lcc}
\hline Parameters & Number & (\%) \\
\hline Anemia (mild to severe) & 70 & 100 \\
Thrombocytopenia & 12 & 17 \\
Hemolytic anemia (Coomb's positive) & 11 & 16 \\
Leukocytopenia & 07 & 10 \\
Raised Urinary Total Protein & 41 & 59 \\
RBC/cast in urine & 18 & 26 \\
ANA positive (IF method) & 68 & 97 \\
Anti ds DNA positive (ELISA) & 64 & 91 \\
Low C 3 & 58 & 83 \\
Low C & 56 & 80 \\
Abnormal lipid profile & 14 & 20 \\
Anti- cardliolipin antibody positivity & 06 & 09 \\
\hline
\end{tabular}

Forty six pediatric SLE patients in our series (65.7\%) had evidences of renal involvement manifested by raised urinary total protein or RBC and cast in urine. Among them, 42 children underwent kidney biopsy (other 4 did not give consent). Majority of these children (40\%) had diffuse proliferative lupus nephritis (WHO class IV), followed by WHO class III nephritis (focal proliferative lupus nephritis) in $26 \%$ and $\mathrm{WHO}$ class II nephritis (mesangial lupus nephritis) in 24\% cases. WHO class $\mathrm{V}$ (membranous lupus nephritis) was found in $4.7 \%$ cases (Table-III).

Table-III

Kidney biopsy findings according to WHO classification $(n=42)$

\begin{tabular}{lcc}
\hline Results & Number & (\%) \\
\hline Class II Nephritis & 10 & 24 \\
Class III Nephritis & 11 & 26 \\
Class IV Nephritis & 17 & 40 \\
Class V Nephritis & 02 & 4.7 \\
No tissue found & 02 & 4.7 \\
\hline
\end{tabular}

Twenty six percent of our SLE patients had neuropsychiatric manifestations at presentation. Pulmonary and cardiac involvement was present in $10 \%$ and $06 \%$ cases respectively (Table-IV).

The clinical and laboratory findings of childhood SLE patients from Bangladesh are compared to other childhood SLE series from India, Philippines, Oman, France, Europe and Egypt. The comparison is shown in Table-IV.

Table-IV

Clinical and Laboratory findings of pediatric SLE cases at diagnosis compared to other studies

\begin{tabular}{|c|c|c|c|c|c|c|c|}
\hline $\begin{array}{l}\text { Number of patients (n) } \\
\text { Country }\end{array}$ & $\begin{array}{c}\text { Present } \\
\text { study } \\
70 \\
\text { Bangladesh }\end{array}$ & $\begin{array}{c}\text { Kumar } \\
2010 \\
20 \\
\text { Indian }\end{array}$ & $\begin{array}{c}\text { Gulay } \\
2011 \\
78 \\
\text { Philippines }\end{array}$ & $\begin{array}{c}\text { Abdwani } \\
2008 \\
50 \\
\text { Oman }\end{array}$ & $\begin{array}{c}\text { Bader- } \\
\text { Munier } 2005 \\
155 \\
\text { France }\end{array}$ & $\begin{array}{l}\text { Hoffman } \\
2009 \\
56 \\
\text { Europe }\end{array}$ & $\begin{array}{c}\text { Bakr A } \\
2005 \\
52 \\
\text { Egypt }\end{array}$ \\
\hline Age at diagnosis in years Mean $( \pm)$ & $11.62 \pm 2.6$ & 11.8 & $14 \pm 2.7$ & 8.6 & $11.5 \pm 2.5$ & 15 & $11.9 \pm 2.6$ \\
\hline Range & $(2.5-16)$ & $(0.5-17)$ & $(8-18)$ & $(4-14)$ & $(1.5-16)$ & $(9-18)$ & $(6-16)$ \\
\hline Female: male ratio & $7: 1$ & 2.3:1 & $10: 1$ & $5.3: 1$ & $4.5: 1$ & $5.2: 1$ & $12: 1$ \\
\hline Fever (\%) & 83 & 75 & 52.5 & 62 & 58 & 67 & 77 \\
\hline Fatigue (\%) & 91 & - & 28.2 & - & - & 78.6 & - \\
\hline MSK problems (\%) & 74 & 65 & 54 & 76 & 64 & 75 & 65 \\
\hline Cutaneous (\%) & 71 & 25 & 65 & 70 & 70 & 69.6 & 46 \\
\hline Photosensitivity (\%) & 59 & 20 & 55 & - & - & 45 & 21 \\
\hline Oral ulcer (\%) & 58 & 25 & 54 & 10 & - & 28.6 & 19.6 \\
\hline Anemia (\%) & 100 & 80 & - & - & - & - & - \\
\hline Hemolytic anemia (\%) & 16 & 15 & 8.9 & 60 & - & 38.5 & 51 \\
\hline Thrombocytopenia (\%) & 17 & 35 & 14.1 & 20 & - & 31.5 & 29 \\
\hline Leukopenia (\%) & 10 & - & 15.3 & 14 & - & 63.6 & 27 \\
\hline Renal involvement (\%) & 66 & 55 & 62.8 & 64 & 50 & 63.6 & 81 \\
\hline Neuropsychiatric involvement (\%) & 26 & 30 & 30.7 & 18 & 17 & - & 7.7 \\
\hline Pulmonary involvement (\%) & 10 & - & 14.1 & 26 & 18 & 18.5 & 9.6 \\
\hline Cardiac involvement (\%) & 06 & 10 & 15.3 & 10 & - & 16.7 & 7.7 \\
\hline
\end{tabular}




\section{Discussion:}

This retrospective cohort study was carried out with the objective of describing the presentation of childhood SLE cases in Bangladesh and comparing it with some other published reports.

We studied the clinical and serological presentation of 70 childhood SLE cases of Bangladesh for the first time and compared the clinical presentation with the childhood SLE series of other countries to identify any variations. As it was performed in a tertiary referral hospital, the study may not represent all the cases of childhood SLE in Bangladesh. It may however give an insight about these patients.

In our series, mean age at diagnosis was 11.62 (SD 2.6) years, which was comparable to other studies (Table 4). Age range of our series was 2.5 years to 16 years. Upper age limit (16 years) was comparable to other studies but lower age limit was variable in different studies. Female preponderance, similar with other reports, may be due to the importance of hormonal factors in the clinical expression of the disease.

General weakness/fatigue was the most common clinical presentation (91\%) in this series followed by fever (83\%). Constitutional symptoms such as fatigue, fever and weight loss are reported to be very common presentation of childhood SLE1 ${ }^{10}$. This fact was also supported by the study.

Arthralgia or arthritis was present in $74 \%$ and skin rash (malar rash and non specific rash) in 71\% children. Kumar et al in their study found fever as the commonest clinical feature at presentation (75\%) followed by Musculo-skeletal (MSK) problems (65\%) in India ${ }^{11}$. On the other hand Gulay et al in Philippines found malar rash as the most common (65.3\%) presentation in their series ${ }^{12}$. Studies done in $\mathrm{Oman}^{13}$ and France ${ }^{14}$ found musculo-skeletal ( $76 \%$ and $\left.64 \%\right)$ and cutaneous problems (70\%) as common presentations, whereas a multi-centered study done in Europe found fatigue as the most common (78.6\%) presentation ${ }^{15}$. Bakr A et al in their study done in Egypt $^{16}$ found fever and musculo-skeletal problems (77\% and 65\%) as common presentations.

In the current series $100 \%$ of the patients had anaemia (ranging from mild to severe). In Indian series 80\% had anaemia ${ }^{11}$. Sixteen percent of our SLE patients had (Coomb's positive) autoimmune haemolytic anaemia which is almost similar to the Indian ${ }^{11}$ and Filipino $^{12}$ studies having $15 \%$ and $8.9 \%$ auto immune haemolytic anaemia at presentation. On the contrary, Abdwani et al ${ }^{12}$ in their study done in Oman found $60 \%$ cases of haemolytic anaemia in their series. Similarly Hoffman et $\mathrm{al}^{15}$ and Bakr et al ${ }^{16}$ in their European and Egyptian series found 38.5\% and 51\% cases of haemolytic anaemia at presentation.

This study found that $66 \%$ of pSLE patients had renal involvement at presentation which was in concordance with the Filipino ${ }^{12}$, Omani $^{13}$ and European studies ${ }^{15}$ but lower than Egyptian ${ }^{16}$ and higher than Indian ${ }^{11}$ and French ${ }^{14}$ studies. Among the patients who underwent renal biopsy, $40 \%$ in this series had Class IV, followed by class III nephritis (WHO). Gulay et al in their Filipino study found similar findings ${ }^{12}$. Reports of nephritis among these compared studies were highest in Egypt $(81 \%)^{16}$ and lowest in France $(50 \%)^{14}$. These diverse presentations appear to be multifactorial. It is reported that socioeconomic, environmental, demographic, psychosocial and genetic factors may play an important role as determinants of ethnic differences in clinical manifestations of SLE patients ${ }^{17}$.

It is important to mention here that, many of the nephritic presentation cases of childhood SLE including renal failure might have gone to the nephrologists for their management and were not included in this series. This would perhaps introduce a bias in the type of patients seen by our group. It may be possible that percentage of renal involvement of pSLE cases in our country may be even higher than what we have found.

The second most common organ involvement at presentation in our series was neuropsychiatric involvement (26\%). This was almost in concordance with other compared studies ${ }^{11-16}$. Our patients had relatively much lower cardiac (06\%) and pulmonary $(10 \%)$ involvements. The reasons for this lower rate of involvements are not clear. But it may be possible that, echocardiogram or chest CT scans in this study was performed only on the symptomatic SLE patients. If these investigations could have been done to all the studied patients, percentage of cardiac and pulmonary involvement could have gone higher.

ANA positivity was $97 \%$ in our study. This finding was almost similar with Gulay et al ${ }^{12}$ and Bakr A study ${ }^{16}$. Low C3 was found in 83\% of our cases which was almost similar with Bakr A study ${ }^{14}$ but much higher than Gulay et al study ${ }^{12}$. 
Few studies are done comparing the clinical presentation of childhood and adult SLE. Renal and haematologic abnormalities were more common at presentation in one comparative study ${ }^{18}$. Another multiethnic disease cohort showed that childhood SLE had significantly more renal and neurological involvement at the time of entry into the study. Pediatric patients also had more active disease at diagnosis, as measured by valid disease activity measure ${ }^{19}$. Joseph et al in their study showed that nephropathy, fever, and lymphadenopathy were more common in childhood onset SLE patients ${ }^{20}$. The present study also found very high incidence of fever, renal involvement and neuropsychiatric involvement among pediatric SLE patients along with non-specific clinical manifestations.

\section{Conclusion:}

This study emphasizes that childhood SLE can present with non-specific and protean clinical manifestations. A high index of suspicion is very much needed for diagnosing pSLE. SLE should be excluded in cases of pyrexia of unknown origin (PUO) and nonspecific general weakness in patients especially in adolescent girls where no specific causes are present. At presentation, our patients had some similarities as well as some differences compared to previous reports from different countries. Further study with a large sample size including both hospitals and community is needed to draw a definite conclusion.

\section{References:}

1. Silverman E, Eddy A. Systemic Lupus Erythematosus. In: Cassidy JT, Petty RE, Laxer RM, Lindsley CB, editors. Text book of Pediatric Rheumatology $6^{\text {th }}$ edition. Philadelphia: Elsevier Saunders; 2011. P. 315-343.

2. Ardroin SP, Schanberg LE. Systemic Lupus Erythematosus. In: Kliegman RM, Stanton BF, Geme III JW St, Schor NF, Behrman RE, editors. Nelson Textbook of peidatrics. $19^{\text {th }}$ edition. Philadelphia: Elsevier Saunders; 2012. P. 841846.

3. Benseler SM. Silverman ED. Systemic Lupus Erythematosus. Pediatr Clin N Am 2005; 52 (2): 443-67.

4. Pineles D, Valente A, Warren B, Peterson MGE, Lehman TJA, Moorthy LN. Worldwide incidence and prevalence of pediatric onset systemic lupus erythematomsus. Lupus 2011; 20: 1187-92.
5. Hiraki LT, Susanne M.B, Tyrrell PN, Harvey E, Hebert D, Silverman ED. Ethnic Differences in Pediatric Systemic Lupus Erythematosus. J Rheum 2009; 36: 2539-46.

6. Lau CS, Yin G, Mok MY. Ethnic and geographical differences in systemic lupus erythematosus: an overview. Lupus 2006; 15: 715-19.

7. Mina R, Brunner HI. Pediatric lupus-Are there differences in presentation, genetics, response to therapy, damage accrual compared to adult lupus? Rheum Dis Clin N Am. 2010; 36 (1): 53-80.

8. Rahman SA. Presentation of childhood SLE: Are we missing cases? Experience from a tertiary hospital in Bangladesh. International J Rheumatic Diseases 2008; 11 (Supple 1): A 514.

9. Weening JJ, D'Agati VD, Schwartz MM, Seshan SV, Alpers CE, Appel GB et al. The classification of glomerulonephritis in Systemic Lupus Erythematosus revisited. JAm Soc Nephrol 2004; 15: 241-250.

10. Tucker LB. Review: Making the diagnosis of systemic lupus erythematosus in children and adolescents. Lupus 2007; 16: 546-549.

11. Kumar S, Nair S, Rajam L. Case series of Pediatric systemic lupuserythematosus from Kerala: comparison with other Indian series. International Journal of Rheumatic Diseases 2010; 13: 391-395.

12. Gulay CB, Dans LF. Clinical presentations and outcomes of Filipino juvenile systemic lupus erythematosus. Pediatric Rheumatology 2011; 9:1-7.

13. Abdwani R, Rizvi SG, El-Nour I. Childhood systemic lupus erythematosus in Sultanate of Oman: demographic and clinical analysis. Lupus 2008; 17: 683-686.

14. Bader-Meunier B, Armengaud JB, Haddad E, Salomon R, Deschenes G, Kone-Paut I et al. Initial presentation of childhood onset systemic lupus erythematosus: A French multicenter study. J pediatr 2005; 146: 648-653.

15. Hoffman IEA, Lauwery BR, De Keyser F, Huizinga $T W$, Isenberg $D$, Cebecauer $L$ et al. Juvenile-onset systemic lupus erythematosus: different clinical and serological pattern than 
adult-onset systemic lupus erythematosus. Ann Rheum Dis 2009; 68: 412-415.

16. Bakr A. Epidemiology treatment and outcome of childhood systemic lupus erythematosus in Egypt. Paediatr Nephrol 2005; 20: 1081-1086.

17. Fernandez M, Alarcon GS, Calvo-Alen J, Andrade R, McGwin G Jr, Villa I, Raveille J, Lumina study group: a multiethnic, multicenter cohort of patients with systemic lupus erythematosus (SLE) as a model for the study of ethnic disparities in SLE. Arthritis \& Rheum 2007; 57(4): 576-584.

18. Tucker LB, Menon S, Schaller JG, Isenberg DA. Adult and childhood onset systemic lupus erythematosus: a comparison of onset, clinical features, serology, and outcome. Br. J Rheumatol 1995; 34 (9): 866-872.

19. Tucker LB, Uribe AG, Fernandez M, Vila LM, McGuine G, Apte M et al. Adolescent onset of lupus results in more aggressive disease and worse outcomes: results of a nested matched case-control study within LUMINA, a multi ethnic US cohort (LUMINA LVII). Lupus2008; 17 (4): 314-22.

20. Font J, Cervera R, Espinosa G, Pallares L, Casals MR, Jimenez $S$ et al. Systemic lupus erythematosus(SLE) in childhood: analysis of clinical and immunological findings in 34 patients and comparison with SLE characteristics in adults. Ann Rheum Dis 1998; 57: 456-459. 